
\title{
25 Research Square \\ Structural and Thermal Studies of Fluorescein and Rhodamin6G Grafted Diblock Copolymers
}

Ramasamy Anbarasan ( $\square$ anbu_may3@yahoo.co.in )

National Taiwan University https://orcid.org/0000-0002-7728-4457

B. Meenarathi

Department of Polymer Technology

V. Parthasarathy

Hindustan Institute of Technology and Science

\section{Original Research Full Papers}

Keywords: ROP, $\varepsilon$-caprolactone, THF, dyes, FT-IR, FE-SEM

Posted Date: February 3rd, 2021

DOI: https://doi.org/10.21203/rs.3.rs-161075/v1

License: (1) This work is licensed under a Creative Commons Attribution 4.0 International License.

Read Full License

Version of Record: A version of this preprint was published at Journal of Inorganic and Organometallic Polymers and Materials on April 9th, 2021. See the published version at https://doi.org/10.1007/s10904021-01978-3. 


\section{Abstract}

The ring-opening polymerization (ROP) of tetrahydrofuran (THF) and $\varepsilon$-caprolactone (CL) was performed at $160^{\circ} \mathrm{C}$ for $2 \mathrm{hr}$ under $\mathrm{N}_{2}$ ambiance by using two different dyes such as fluorescein (Flur) and rhodamine6G (R6G) as novel initiators. The structure of the dye centered diblock copolymers was concluded by analyzing the NMR spectra. The melt transition temperature and thermal stability of the polymers were concluded by DSC and TGA. The FT-IR spectra concluded the structure of the dye grafted homopolymer and diblock copolymers. The increase in molecular weight $\left(\mathrm{M}_{\mathrm{w}}\right)$ of the dye-centered diblock copolymer was concluded by the GPC measurement. The conjugation of dye with the polymer backbone was carried out by a single-step method.

\section{Introduction}

Recently, the biomedical polymers such as poly(tetrahydrofuran) (PTHF) and poly( $₫$-caprolactone) (PCL) have been received much attention because of their biocompatibility and less cytotoxicity. They are prepared by the ROP technique in the presence of a catalyst and an initiator. Generally, Sn salts are used as a catalyst in the presence of various initiators. The catalytic efficiency of $\mathrm{FeCl}_{3}$ on the ROP of THF was studied by Yang et al. [1]. The chloromethylaryloyl was employed as an initiator for the ROP of THF by Kohsaka et al. [2]. Nomura et al. [3] reported the ROP of THF using the vanadium complexes as a catalyst [4]. Zhang et al. [5] investigated the initiating efficiency of alkoxides towards the anionic ROP of THF. Bodulla and his research team [6] studied the ROP of THF using reusable poly(aniline) as a catalyst. Marchetti et al. [7] examined the initiating efficiency of niobium and tantalum halides towards the ROP of THF. The kaolin was used as an acid catalyst in the preparation of the ROP of THF [8]. The metal ion was employed as an initiator for the charge-transfer photopolymerization of THF by Woodhouse et al. [9]. Olah et al. [10] studied the cationic ROP of THF using the Al and gallium tristriflate as a catalyst. The reports on Flur and R6G initiated ROP of THF are scarce in the literature. The significance of this present work is to prepare the fluorescent dye tagged PTHF without using any hazardous solvents during the synthesis process.

PCL is a bio-medically important polymer. The synthesis of PCL is performed in the presence of various catalysts and initiator systems. Here also, SO plays a significant role in the ROP of CL as a catalyst. Initiators like pullulan [11], heparin [12], chitin [13], Ag-kaolinite [14] and palygorskite were used for the

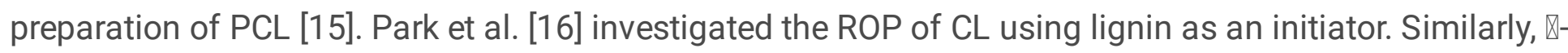
aminoacids [17], $\mathrm{Fe}_{3} \mathrm{O}_{4}$ nanoparticles [18], n-butanol [19], L-proline [20] and cellulose [21] were employed as an initiator for the ROP of CL [22]. Barium mercaptoacetate had been used as a lone chemical initiator for the polymerization of $\mathrm{CL}$ [23]. The $\mathrm{Fe}_{3} \mathrm{O}_{4}$ /congored nanohybrid was used as an initiator for the polymerization of CL by ROP [24]. Agathian et al. [25] studied the ROP of CL using the cotton fiber as an initiator. The reports on the dye conjugated PCL are scarce in the literature. This study intends to prepare the dye grafted PCL without using any hazardous solvents during its synthesis in a single-step process. 
Flur is an organic dye which exhibits the monomeric and dimeric structure in an aqueous medium. Flur is used as a fluorescent probe in the biomedical sectors [26]. R6G is a dye belonging to a rhodamine family. It is soluble in alcohol and water. It is used as a laser dye with a $\lambda_{\max }$ value of $532 \mathrm{~nm}$ [27]. In the present work, two different dyes are used as an initiator towards the ROP of THF and CL. The initiating efficiency of the proposed dyes on the $\mathrm{M}_{\mathrm{w}}$, absorbance (UV-visible), emission (Fluorescence), melt transition temperature $\left(T_{m}\right)$, degradation temperature $\left(T_{d}\right)$ and surface morphology of prepared PCL was studied and compared. The - $\mathrm{OH}$ is an active group in Flur dye, whereas the - $\mathrm{NH}$ is an active group in $\mathrm{R} 6 \mathrm{G}$ towards the ROP reaction. Sivabalan et al. [28] studied the ROP efficiency of various functional groups towards the polymerization of $\mathrm{CL}$ by ROP. It was also concluded that the -OH is a highly active group for the polymerization of $\mathrm{CL}$. For this purpose, the Flur and R6G dyes were selected as an initiator. In biomedical engineering, the dyes are generally used as a fluorescent probe. The chemical conjugation of dye with the polymer backbone is a two-step process, and it is also a time consuming one. In this work, the dye molecule is acting as an initiator for the polymerization of $\mathrm{CL}$. Hence, the dye is acting as a fluorescent probe and an initiator. Moreover, PCL and PTHF are biodegradable and biocompatible. The main aim of

this work is to synthesis the fluorescent probe containing diblock copolymer without using any hazardous solvents in a cost-effective manner. In the bio-medical industry, a biodegradable polymer-based fluorescent probe is prepared by a multi-step process using some hazardous solvents. The significance of the present work is to prepare the same fluorescent probe by a single-step method without using any hazardous solvents.

\section{Experimental}

\subsection{Materials}

Tetrahydrofuran (THF, co-monomer), stannous octoate (SO, catalyst) and $\varepsilon$-caprolactone (CL, monomer) were received from Merck, India. Fluorescein (Flur, initiator), rhodamine6G (R6G, initiator) and phthalic anhydride ( $\mathrm{PAH}$, accelerator), chloroform $\left(\mathrm{CHCl}_{3}\right.$, solvent) and diethyl ether (non-solvent) were obtained from Aldrich, India.

\subsection{Procedure}

The preparation of dye grafted PTHF and PCL was carried out in two consecutive steps. A homopolymer was prepared by using dye as a chemical initiator in the first step. In the next step, a diblock copolymer was synthesized by using the prepared homopolymer as a chemical initiator.

\subsection{Preparation of homopolymer (Dye-PCL) (P1 and P3 systems)}

The homopolymer of dye grafted PCL was synthesized by using a standard literature procedure [28]. The procedure is described briefly: $2 \mathrm{~g}$ of $\mathrm{CL}(\mathrm{M}), 0.001 \mathrm{~g}$ of $\mathrm{SO}(\mathrm{C})$ and $0.01 \mathrm{~g}$ of dye (I) were taken together in a $25 \mathrm{~mL}$ RB flask. This mixture was heated at $160^{\circ} \mathrm{C}$ for $2 \mathrm{hr}$ in an oil bath under the $\mathrm{N}_{2}$ ambiance. The monomer to catalyst [M/C] and monomer to initiator [M/I] ratios were kept as 1000 and 100 respectively. 
The liquid monomer, catalyst and solid initiator are miscible with each other completely under this experimental condition. In the absence of either catalyst or initiator, the ROP of CL is absent. This proved the requirement of a functional group-containing initiator for the polymerization of $\mathrm{CL}$. The SO accelerates the reaction via the co-ordination insertion mechanism, which yields the highly viscous product. This proves the polymerization of $\mathrm{CL}$ by ROP in the presence of a catalyst (C) and initiator (I). The resultant highly viscous product was evaporated to dryness under a fume hood overnight. The final obtained products are named as P1 for Flur dye end-capped system and P3 for the R6G dye end-capped system. The reaction mechanism for the same is illustrated in Scheme 1\&2.

\subsection{Preparation of diblock copolymer (PCL-Dye-PTHF) (P2 and P4 systems)}

The diblock copolymer of PCL-Dye-PTHF was also prepared as follows: $0.50 \mathrm{~g}$ of homopolymer (PCLdye) was taken along with $0.01 \mathrm{~g}$ of PAH in an RB flask $(100 \mathrm{~mL})$. Further, this mixture was added with 20 $\mathrm{mL}$ of THF. Then, it was heated at $45^{\circ} \mathrm{C}$ under $\mathrm{N}_{2}$ ambient for $6 \mathrm{hrs}$. Then, the reaction was completed after the addition of diluted $\mathrm{HCl}(100 \mathrm{~mL})$. Finally. the brown-colored diblock copolymer was obtained by the freeze-drying method. The obtained final products are named as P2 (PCL-Flur-PTHF) and P4 (PCLR6G-PTHF) systems. The reaction scheme is illustrated in Scheme $1 \& 2$.

\subsection{Characterizations}

The structural analysis had been performed for the prepared samples by recording the NMR (Bruker $\mathrm{K}$ 8600 instrument, USA) and FTIR spectra (Shimadzu 8400S, Japan) respectively. The morphology of the sample had been investigated by analyzing the recorded SEM micrograph on the JEOL JSM 6300 SEM instrument and FESEM micrograph on FESEM-Hitachi S4800 Japan, respectively. The thermal degradation temperature $\left(T_{d}\right)$ of the samples had been examined by recording the TG thermograms on a Universal V4.4A TA thermal analyzer within the heating range of 30 to $800^{\circ} \mathrm{C} @ 10^{\circ} \mathrm{C} \mathrm{min}^{-1}$ in air ambiance. The melt transition temperature $\left(T_{m}\right)$ of the polymer samples had been studied by recording the DSC thermograms on a Toledo DSC $822 \mathrm{E}$ instrument within the heating range of 30 to $150^{\circ} \mathrm{C}$ under $\mathrm{N}_{2}$ ambiance. The electronic transitions present in the polymer sample had been examined by capturing the UV-visible spectra on a Thermo Nicolet Avatar 370 spectrometer. The fluorescence property of the polymer sample had been inspected using the Elico SL 172, India instrument

\section{Results And Discussion}

It is well known that Flur is a xanthene type dye which consists of hydroxyl, carboxyl, ketone, ether, aromatic $\mathrm{C}=\mathrm{C}$ like functionalities. In the present investigation, the ROP of $\mathrm{CL}$ and THF in the presence of $\mathrm{PAH}$ is analyzed. The various functional groups of R6G are ester, ether and secondary amine cation, etc. However, the secondary amine group is highly active for the polymerization of CL by ROP.

\subsection{FT-IR spectroscopy}


The FT-IR spectra of P1 and P2 systems are illustrated in Fig. 1a \& b respectively. The stretching of symmetric and antisymmetric modes of aliphatic $\mathrm{C}-\mathrm{H}$ are seen at 2868 and $2942 \mathrm{~cm}^{-1}$ respectively. The peaks corresponding to symmetric and antisymmetric modes of aromatic C-H are noticed at 2524 and $2650 \mathrm{~cm}^{-1}$ respectively. A peak at $1730 \mathrm{~cm}^{-1}$ is linked to the stretching of the carbonyl group of PCL [25]. The out of plane bending of $\mathrm{C}-\mathrm{H}$ vibration and linkage of $\mathrm{C}-\mathrm{O}-\mathrm{C}$ are seen at $733 \mathrm{~cm}^{-1}$ and $1183 \mathrm{~cm}^{-1}$ respectively. After the diblock copolymer formation, some new peaks are assigned for THF and PAH segments. The important peaks are encircled in the spectrum. The stretching of aromatic symmetric and anti-symmetric modes are noted. The stretching of the carbonyl group is assigned as a doublet peak. The short humps at $1693 \mathrm{~cm}^{-1}$ and $1730 \mathrm{~cm}^{-1}$ are corresponding to the stretching of the carbonyl group of PAH and PCL [25]. The stretching of tetrahydrofuronium ion appeared as a short peak at $1582 \mathrm{~cm}^{-1}$. The aromatic $\mathrm{C}-\mathrm{H}$ deformations are seen at 666 and $799 \mathrm{~cm}^{-1}$ which concluded the diblock copolymer formation. The FT-IR spectrum of the P3 system exhibits the stretching modes of $-\mathrm{OH}\left(3440 \mathrm{~cm}^{-1}\right), \mathrm{C}-\mathrm{H}$ (2872 and $\left.2949 \mathrm{~cm}^{-1}\right)$, carbonyl $\left(1730 \mathrm{~cm}^{-1}\right)$ [25], C-N $\left(1366 \mathrm{~cm}^{-1}\right), \mathrm{C}-\mathrm{O}-\mathrm{C}\left(1196 \mathrm{~cm}^{-1}\right)$, and out of plane bending of $\mathrm{C}-\mathrm{H}$ vibration $\left(734 \mathrm{~cm}^{-1}\right)$ as demonstrated in Fig. 1c. The P4 system exhibits some new peaks corresponding to aromatic $\mathrm{C}-\mathrm{H}$ stretching $\left(2528 \mathrm{~cm}^{-1}\right.$ and $\left.2652 \mathrm{~cm}^{-1}\right), \mathrm{C}=0$ stretching $\left(1686 \mathrm{~cm}^{-1}\right.$ corresponding to the $\mathrm{C}=\mathrm{O}$ stretching of $\mathrm{PAH})$ and aromatic $\mathrm{C}-\mathrm{H}$ deformation $\left(665\right.$ and $\left.802 \mathrm{~cm}^{-1}\right)$ as illustrated in Fig. 1d. Hence, the occurrence of new peaks proved the ROP of THF while using PAH as an accelerator.

\subsection{NMR analysis}

The structure of homo and diblock copolymer was concluded by NMR spectroscopy. Figures $2 \mathrm{~A}$ and $\mathrm{B}$ denote ${ }^{1} \mathrm{H}$ - and ${ }^{13} \mathrm{C}$-NMR spectra of the $\mathrm{P} 1$ system. A signal for standard TMS is noticed at $0 \mathrm{ppm}$. The alkoxy proton signal of $\mathrm{PCL}$ is seen at $4.12 \mathrm{ppm}$. A signal at $2.3 \mathrm{ppm}$ is due to the proton of $-\mathrm{CO}_{2} \mathrm{CH}_{2}$. A signal at $3.8 \mathrm{ppm}$ is corresponding to $-\mathrm{CH}_{2}$ proton of $\mathrm{PCL}$ [23]. A peak at $7.3 \mathrm{ppm}$ is owing to the $\mathrm{CDCl}_{3}$ solvent. The ${ }^{13} \mathrm{C}-\mathrm{NMR}$ spectrum of the $\mathrm{P} 1$ system exhibits a signal for carbonyl carbon at $173 \mathrm{ppm}$ (Figs. 2B). A signal at $64 \mathrm{ppm}$ is linked to the signal of alkoxy carbon. The signals for other carbon are assigned between 20 and $40 \mathrm{ppm}$. Thus the NMR spectra concluded the structure of the P1 system. The ${ }^{1} \mathrm{H}$ - and ${ }^{13} \mathrm{C}$-NMR spectra of the $\mathrm{P} 2$ system are demonstrated in Fig. $2 \mathrm{C}$ and $\mathrm{D}$ respectively. This system also showed the above-discussed peaks. However, there were no proton and carbon signals associating with the THF segments. It is really due to the non-solvating behavior of the PTHF units in $\mathrm{CDCl}_{3}$ solvent. Figure $3 \mathrm{~A}$ represents the ${ }^{1} \mathrm{H}$-NMR spectrum of the $\mathrm{P} 3$ sample. The signals for the aromatic protons of R6G are identified between 6.2 and $8.2 \mathrm{ppm}$. The sharp peaks at $4.1 \mathrm{ppm}$ and $2.2 \mathrm{ppm}$ are attributing to the $-\mathrm{OCH}_{2}$ and $-\mathrm{CO}_{2} \mathrm{CH}_{2}$ protons of PCL [22]. The other methylene protons are assigned between 1 and $1.8 \mathrm{ppm}$. A signal for $\mathrm{CH}_{2}$ protons of PCL occurs at $3.7 \mathrm{ppm}$. The occurrence of peaks associating with the aromatic and alkoxy protons proved the ROP of CL by R6G. The ${ }^{13} \mathrm{C}-\mathrm{NMR}$ spectrum of the P3 sample is illustrated in Fig. 3B. A signal at 172 ppm is related to the carbonyl carbon signal of PCL [23]. A peak at $62 \mathrm{ppm}$ is assigned to the signal for alkoxy carbon. The other carbon signals are related to the structure of PCL. The ${ }^{1} \mathrm{H}-\mathrm{NMR}$ spectrum of the P4 system is represented in Fig. $3 \mathrm{C}$. This system also showed the 
above-discussed peaks corresponding to the structure of PCL. The proton signals for THF units did not appear owing to the poor solvation effect. The ${ }^{13} \mathrm{C}$-NMR spectrum of the P4 sample is represented in Fig. 3D. The signals corresponding to THF segments are absent due to poor salvation effect.

\subsection{UV-visible spectral analysis}

Figure 4a demonstrates the UV-visible spectrum of pristine Flur. It exhibited one absorption peak at 490 $\mathrm{nm}$ relating to the monomeric structure of Flur [29]. The absorbance peak was highly suppressed for the P1 (Fig. 4b) and P2 (Fig. 4c) systems. This is due to the degradation of Flur dye at $160{ }^{\circ} \mathrm{C}$. The $-\mathrm{OH}$ group of Flur is active towards the ROP of CL. Moreover, the carboxyl group of Flur is active only for the polymerization of THF in the presence of PAH as an accelerator. But it is proved that Flur is degraded at a lower temperature since it is not having any halogen or nitro group. Figure $4 \mathrm{~d}$ illustrates the UV-visible spectrum of pure R6G. The absorption peaks at $534 \mathrm{~nm}$ (monomeric) and $502 \mathrm{~nm}$ (dimeric) are assigned to the structure of R6G [30]. The P3 system (Fig. 4e) shows an absorption peak at $532 \mathrm{~nm}$ and a small hump at $499 \mathrm{~nm}$ associating with the structure of the R6G. The UV-visible absorption spectrum of the P4 system shows a peak at $528 \mathrm{~nm}$ due to the monomeric form of R6G (Fig. 4f). The absorption peak for R6G was blue-shifted during the ROP of THF and CL. This explains the decrease in the conjugation length of R6G. This can also be explained by the decrease in the size of R6G during the ROP of THF and CL. In comparison, the xanthene type dyes (Flur) are not suitable for the ROP of $\mathrm{CL}$ at $160{ }^{\circ} \mathrm{C}$, whereas the R6G dye is stable at the same experimental conditions. In our previous publications [31], a similar effect was observed while using xanthene type dyes.

\subsection{Fluorescence emission spectrum (FES) study}

Flur is a well-known dye molecule, and it can exhibit a fluorescence property. The FES spectra of the P1 (Fig. 5a) and P2 systems (Fig. 5b) are given here for the sake of comparison. Both the spectra showed an emission peak at $521 \mathrm{~nm}$ [29]. Unfortunately, the peak's intensity was found to be very low. This may be due to (i) the presence of a low quantity of dye molecules, (ii) degradation of Flur dye during the ROP of $\mathrm{CL}$ at $160^{\circ} \mathrm{C}$ for 2 hours. Generally, both homopolymer and diblock copolymer exhibited a very low intensity than the pristine Flur dye. This suggests that the degradation of Flur dye may occur during the polymerization of CL. The FES of the P3 sample exhibits an intensity of $80 \mathrm{cps}$ at $563 \mathrm{~nm}$ [30] as illustrated in Fig. 5c. The peak is red-shifted to $568 \mathrm{~nm}$ for the P4 sample after the formation of the diblock copolymer (Fig. 5d). This concluded the ROP of THF and CL in the presence of R6G dye initiator.

\subsection{DSC analysis}

$P C L$ is a semi-crystalline polymer, and hence it exhibits a melt transition peak $\left(T_{m}\right)$. The $T_{m}$ was found to be $68.1^{\circ} \mathrm{C}$ (Table 1) for the P1 system as demonstrated in Fig. 6a [30]. The $T_{m}$ value of the P2 system was decreased to $64.5^{\circ} \mathrm{C}$ (Fig. 6b). This indicates that the $T_{m}$ value of the PTHF is almost equal to the $T_{m}$ of PCL. It absorbs moisture due to hydrophilic nature. Hence, there is a reduction in $T_{m}$ value. The endothermic peak was observed at $63.8^{\circ} \mathrm{C}$ for the P3 system [25] attributing to the $T_{m}$ of PCL (Fig. 6c). The DSC thermogram of the P4 system exhibited the $T_{m}$ at $61.2^{\circ} \mathrm{C}$ (Fig. $6 \mathrm{~d}$ ). In comparison, the diblock 
copolymer exhibited lower $T_{m}$ value than the homo PCL. The appearance of a single $T_{m}$ confirmed the homogeneity of the diblock copolymer. In the overall comparison, the homopolymer exhibited higher $\mathrm{T}_{\mathrm{m}}$ values, and particularly the Flur dye yielded a higher $\mathrm{T}_{\mathrm{m}}$ value. The $\mathrm{P} 1$ sample exhibited the highest $\mathrm{T}_{\mathrm{m}}$ value of $68.1^{\circ} \mathrm{C}$ owing to the hydrophobic nature of PCL.

Table 1 DSC, TGA and GPC data

\begin{tabular}{|c|c|c|c|c|c|c|c|}
\hline \multirow[t]{2}{*}{ System } & \multirow[t]{2}{*}{ Code } & \multirow[t]{2}{*}{$\mathrm{T}_{\mathrm{m}}\left({ }^{\circ} \mathrm{C}\right)$} & \multicolumn{2}{|c|}{$\mathrm{Td}\left({ }^{\circ} \mathrm{C}\right)$} & \multirow{2}{*}{\multicolumn{2}{|c|}{$\begin{array}{l}\mathrm{M}_{\mathrm{w}} \quad \mathrm{M}_{\mathrm{n}} \\
(\mathrm{g} / \text { mole })\end{array}$}} & \multirow[t]{2}{*}{$\mathrm{PD}$} \\
\hline & & & PCL & PTHF & & & \\
\hline PCL-Flur & P1 & 68.1 & 410 & -- & 12763 & 7295 & 1.7 \\
\hline PCL-Flur-PTHF & $\mathrm{P} 2$ & 64.5 & 385 & 200 & 14388 & 8688 & 1.6 \\
\hline PCL-R6G & P3 & 63.8 & 422 & -- & 5516 & 3064 & 1.8 \\
\hline PCL-R6G-PTHF & $\mathrm{P} 4$ & 61.2 & 393 & 214 & 6348 & 3341 & 1.9 \\
\hline
\end{tabular}

The thermal properties of the P1 system were analyzed by TGA. The decomposition of the P1 system occurs in two-steps (Fig. 7a). The major mass loss at $410{ }^{\circ} \mathrm{C}$ (Table 1) is attributing to the decomposition of PCL [31]. The minor mass loss at $500{ }^{\circ} \mathrm{C}$ is responsible for the decomposition of Flur dye attached to the chain end of the PCL. The decomposition of the P2 sample occurs in two-steps (Fig. 7b). The major mass loss at $200{ }^{\circ} \mathrm{C}$ is attributing to the decomposition of PTHF units [22]. The minor mass loss at 385 ${ }^{\circ} \mathrm{C}$ is responsible for the decomposition of PCL. The thermal stability of hydrophobic PCL was higher than the hydrophilic PTHF segments. The decomposition of the P3 system occurs in two-steps (Fig. 7c). The major mass loss at $422^{\circ} \mathrm{C}$ is attributing to the decomposition of PCL. The minor mass loss at $525^{\circ} \mathrm{C}$ is related to the decomposition of the R6G dye. The decomposition of the P4 system occurs in three-steps (Fig. 7d). The minor mass loss at $214^{\circ} \mathrm{C}$ is attributing to the decomposition of PTHF units. The major mass loss at $393^{\circ} \mathrm{C}$ is because of the decomposition of PCL. The minor mass loss at $475{ }^{\circ} \mathrm{C}$ is ascribed to the decomposition of the R6G dye. The homo PCL showed higher thermal stability than the diblock copolymer. This is because of the attached hydrophilic PTHF units to the hydrophobic PCL backbone. In the overall comparison, the $\mathrm{P} 3$ sample revealed the highest $\mathrm{T}_{\mathrm{d}}$ value of $422^{\circ} \mathrm{C}$ for the $\mathrm{R} 6 \mathrm{G}$ end-capped PCL. It means that the R6G dye yielded the highest thermal stability for the PCL system

\subsection{GPC study}

The initiating efficiency of the Flur and R6G dyes on the ROP of THF and CL was confirmed by GPC measurements. The $P 1$ system exhibited the $M_{w}, M_{n}, P D$ values of $12763 \mathrm{~g} / \mathrm{mole}, 7295$ and 1.7 
respectively (Table 1). For the P2 system, the $M_{w}$ was increased to $14388 \mathrm{~g} / \mathrm{mole}$ with the simultaneous increase of $M_{n}$ (8688). This is indicated in Fig. 8a\&b for the prepared P1 and P2 systems. The increase in $M_{w}$ of the P2 system proved the polymerization of THF by the ROP method while using PAH as an accelerator and Flur as a chemical initiator. The GPC profile concluded the polymerization of CL with R6G initiator. The $M_{w}, M_{n}, P D$ values of the $P 3$ system are $5516 \mathrm{~g} / \mathrm{mole}, 3064$ and 1.8 respectively (Fig. 8c). Similarly, the $M_{w}, M_{n}, P D$ values of the $P 4$ system were determined as $6348 \mathrm{~g} / \mathrm{mole}, 3341$, and 1.9 respectively (Fig. 8d). The increase in $\mathrm{M}_{\mathrm{w}}$ proved the ROP of THF while using PAH and R6G as an initiator. As usual, the $\mathrm{M}_{\mathrm{w}}$ of the diblock copolymer was higher than the homopolymer. The R6G initiator system yielded a low molecular weight than the Flur initiator system. This is due to the poor ionizing nature of $\mathrm{NH}$ group. This proved a higher ring-opening capability of $-\mathrm{OH}$ group than the $\mathrm{N}-\mathrm{H}$ group. Sivabalan et al. [28] proved the ROP ability of different functional groups toward CL and also concluded the same.

\subsection{SEM and FE-SEM study}

The surface morphology of the P1 sample is illustrated in Fig. 9a. It seems to be like a dry-sky with some microvoids [31]. These voids can be accommodated by drug molecules while loading drugs. Hence, it proved that PCL is an ideal candidate for drug release applications. The FE-SEM micrograph of the P2 system is demonstrated in Fig. 9b. The morphology looks like a dry-sky with some NPs, and this can be explained as follows. The formation of polymer NPs at the interface of the polymers is due to the combination of hydrophilic PTHF and hydrophobic PCL. The polymer NPs are the key elements for the active drug release process. The size of the particles was estimated as $50-80 \mathrm{~nm}$. Figure $9 \mathrm{c}$ illustrates the SEM micrograph of the P3 system. The surface texture is looking like a broken stone [31] with the spherical particles of size about $800 \mathrm{~nm}$. Here also, one can see the various structures like microvoids and micro rods. The presence of microvoids is very much useful for the drug-carrying purpose. The surface texture of the P4 sample is analyzed by using the FE-SEM image (Fig. 9d). It exhibited a broken stone-like texture with the homogeneously dispersed spherical NP of size approximately $90 \mathrm{~nm}$. The formation of polymer nanoparticle at the interface is due to the interaction of hydrophobic and hydrophilic segments.

\section{Conclusions}

The FT-IR spectra revealed a doublet peak at $1730 \mathrm{~cm}^{-1}$ due to carbonyl stretching of PCL and PAH, which proved the formation of the diblock copolymer. The NMR study confirmed the chemical structure of the homopolymers. The absorption spectra of P1 and P3 systems were highly depressed due to the degradation of the Flur dye. The $T_{m}$ of the diblock copolymer is lower than a homopolymer owing to the hydrophilic behavior of PTHF units. The diblock copolymer has a lower $T_{d}$ value than the homopolymer. Both the initiator systems exhibited the high molecular weight for the prepared diblock copolymers rather than the homopolymer. The FE-SEM image indicated the formation of polymer NPs during the diblock copolymer formation. This study proved that the xanthene type dyes are not suitable for the ROP of CL at 
$160^{\circ} \mathrm{C}$ under the nitrogen atmosphere. At the same time, the R6G dye is an excellent candidate for the ROP of CL and THF under the same experimental conditions.

\section{Declarations}

\section{Conflict of interest}

The authors have no conflicts of interest to declare

\section{References}

1. H.J. Yang, S.W. Yaog, H.S. Park, K.H. Lee, N.H. Hur, J. Appl. Polym. Sci. 136, 47999 (2019)

2. Y. Kohsaka, N. Nagatsuka, Polym. J. 52, 75 (2020)

3. K. Nomura, K. Suzuki, S. Katao, Y. Matsumoto, Organomet. 31, 5114 (2012)

4. S. Kobayashi, H. Danda, T. Saegusa, Bull. Chem. Soc. Jpn 46, 33214 (1973)

5. X. Zhang, X. Fan, X. Zhou, Asian J. Chem. 26, 6391 (2014)

6. R. Bodulla, S.A. Palaniappan, Curr. Green Chem. 3, 346 (2020)

7. F. Marchetti, G. Pampaloni, T. Repo, Eur. J. Inorg. Chem. 12, 2107 (2008)

8. A. Moumen, Z. Hattab, Y. Belhocine, N. Rebbani, Bull. Chem. React. Eng. Catal. 14, 294 (2019)

9. M.E. Woodhouse, F.D. Levis, T.J. Marks, J. Am. Chem. Soc. 104, 5586 (1982)

10. G.A. Olah, O. Farooq, G.H. Li, A. Akklonis, J. Appl. Polym. Sci. 45, 9 (1992)

11. T. Carvalhoa, R.M. Moraesa, G.M. Alvesa, F. Medeino Int. J. Biol. Macromol. 145, 701 (2020)

12. J. Liu, J. Wet, Y. Li, J. Biomater. Sci. Polym. Ed. 31, 1421 (2020)

13. R. Jeyakumar, H. Tamura, Int. J. Biol. Macromol. 43, 32 (2008)

14. F. Benhacine, F.A. Ouargh, A.A.S. Hadjtamel, A.S. Polym. Plast. Technol. Mater. 58, 328 (2019)

15. G. Wang, R. Ma, T. Chen, C. Yan, F. Bao, Polym. Plast. Technol. Mater. 52, 1193 (2013)

16. I.K. Park, H. Sun, S.H. Kim, G.E. Kim, H.R. Chen, Sci. Rep. 9, 7033 (2019)

17. E. Oledjka, K. Sokolowski, M. Sobczab, W. Kolodziejski, Polym. Int. 60, 787 (2011)

18. G.S. Wang, L. Wang, Z.Y. Wei, L. Sang, W.X. Zhang, Chin. J. Polym. Sci. 31, 1011 (2013)

19. D. Wu, Y. Lv, R. Guo, R. Lu, H. Wang, Z. Wei, Macromol. Res. 25, 1070 (2017)

20. J. Liu, L. Liu, Macromolecules 37, 2674 (2004)

21. H. Lonnberg, Q. Zhou, H. Brusser, T.T. Teen, E. Malmstrom, A. Hult, Biomacromol 7, 2178 (2006)

22. M. Jeyapriya, B. Meenarathi, R. Anbarasan, Polym. Bull. 77, 2631 (2020)

23. R. Anbarasan, L. Kannammal, B. Meenarathi, Polym. Bull. 76, 5381 (2019)

24. R. Anbaraan, V. Kohila, B. Meenarathi, G. Jeyalakshmi, A. Jancirani, SN Appl. Sci. 1, 602 (2019)

25. K. Agathian, L. Kannammal, B. Meenarathi, S. Kailash, R. Anbarasan, Int. J. Biol. Macromol. 107, $1102(2018)$ 
26. M. Thomas, Ann. Thorac. Surf. 97, 27 (2014)

27. R.K. Kubin, A.N. J. Lumin 27, 455 (1982)

28. A. Sivabalan, R. Harihara Subramani, B. Meenarathi, S. Palanikumar, R. Anbarasan, Int. J. Sci. Res. Eng. Technol. 1, 9 (2014)

29. R. Sjoback, J. Nygren, M. Kubist, Spectrochim. Acta Part A Mol. Biomol. Spect. 51, 17 (1995)

30. P. Abinayasri, M. Nageswari, B. Meenarathi, R. Anbarasan, Bull. Mater. Sci. 40, 591 (2017)

31. B. Rajkumar, T. Dhanalakshmi, B. Meenarathi, R. Anbarasan, Polym. Bull. 73, 2147 (2016)

\section{Figures}

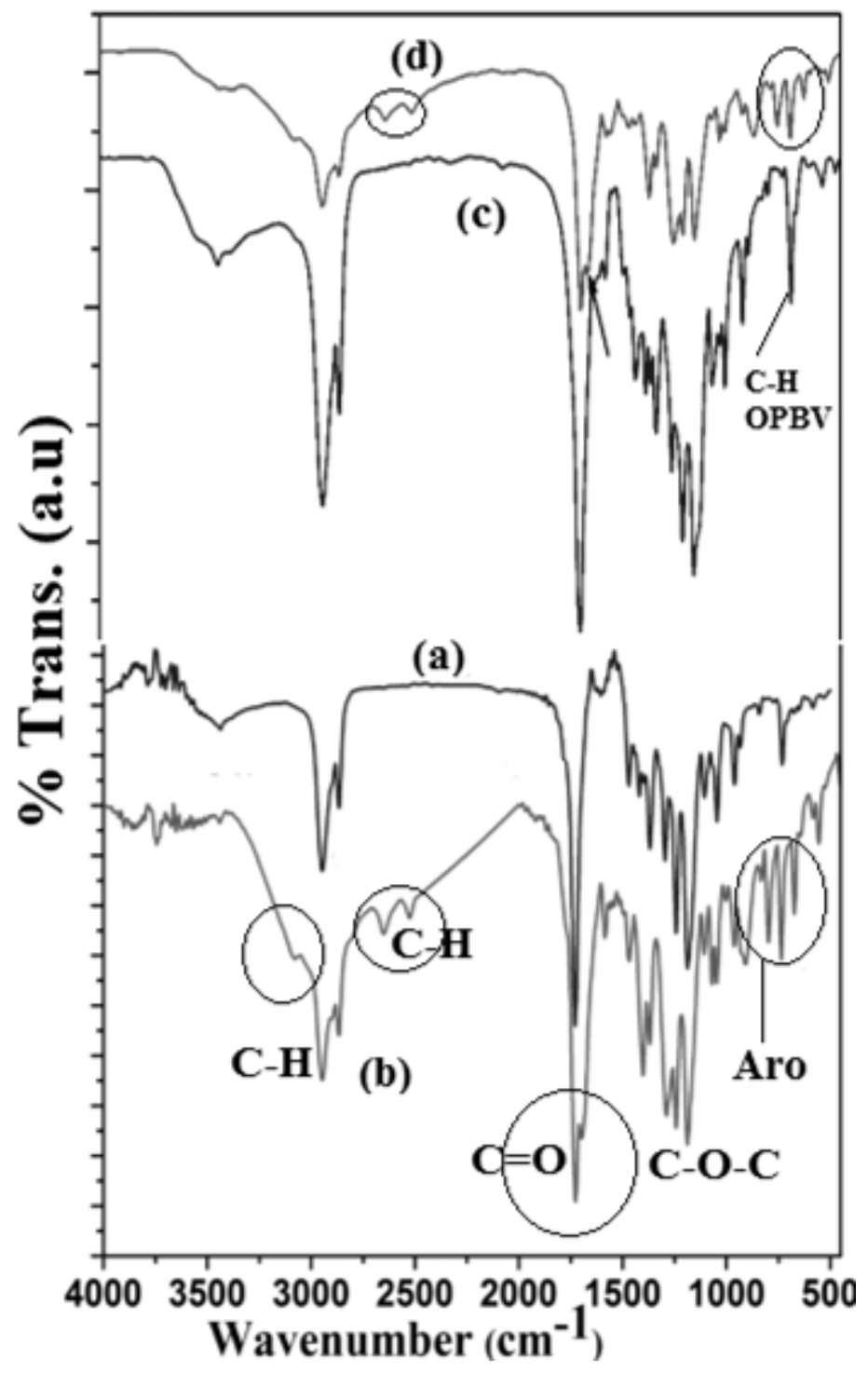

Figure 1

FT-IR spectra of (a) P1 system (b) P2 system (c) P3 system (d) P4 system 

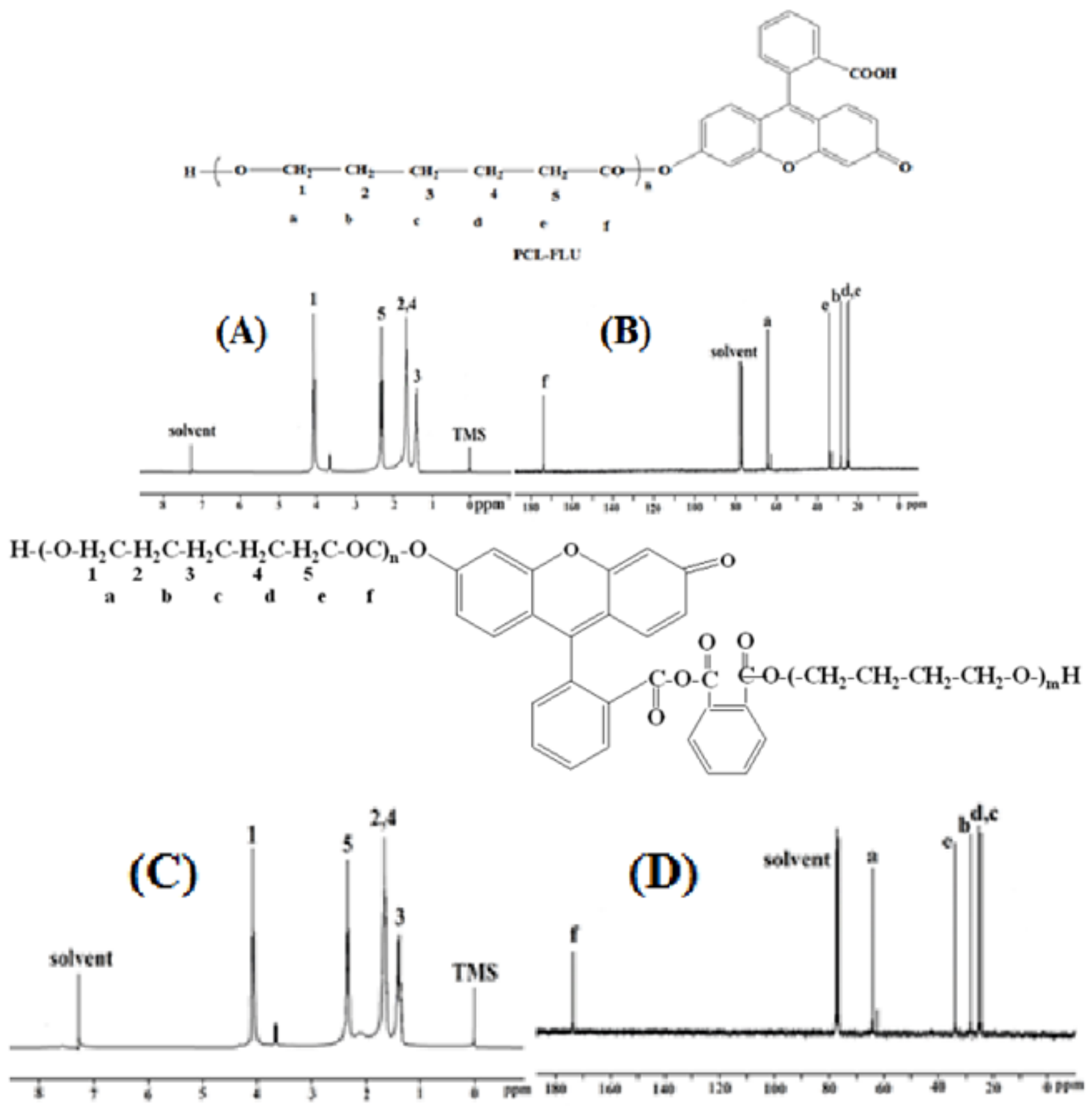

Figure 2

1H-NMR spectra of (A)P1 sample and (C)P2 sample and 13C-NMR spectra of (B)P1 sample and (D)P2 sample. 


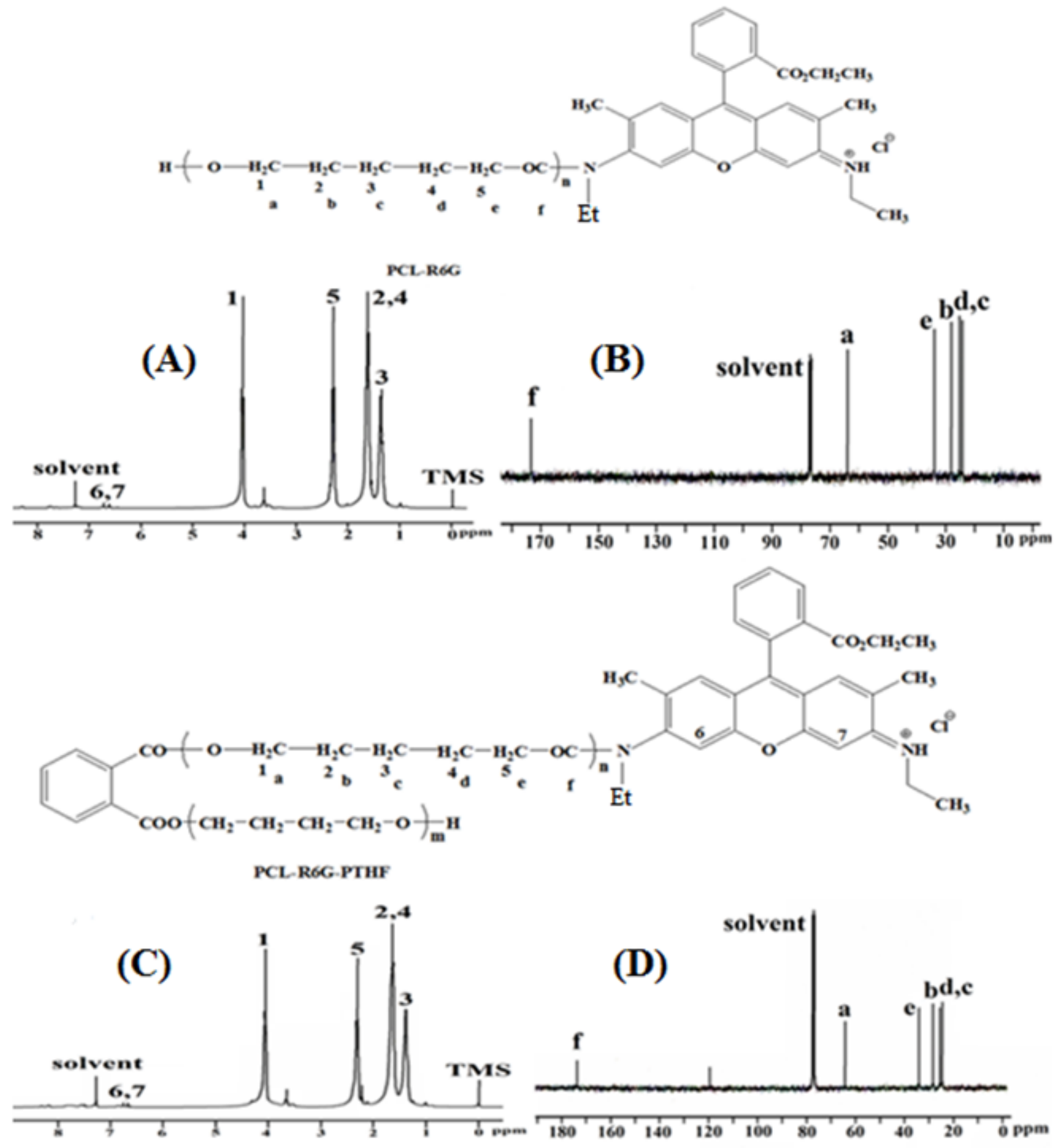

Figure 3

1H-NMR spectra of (A) P3 sample and (C) P4 sample and 13C-NMR spectra of (B) P3 sample and (D) P4 sample. 

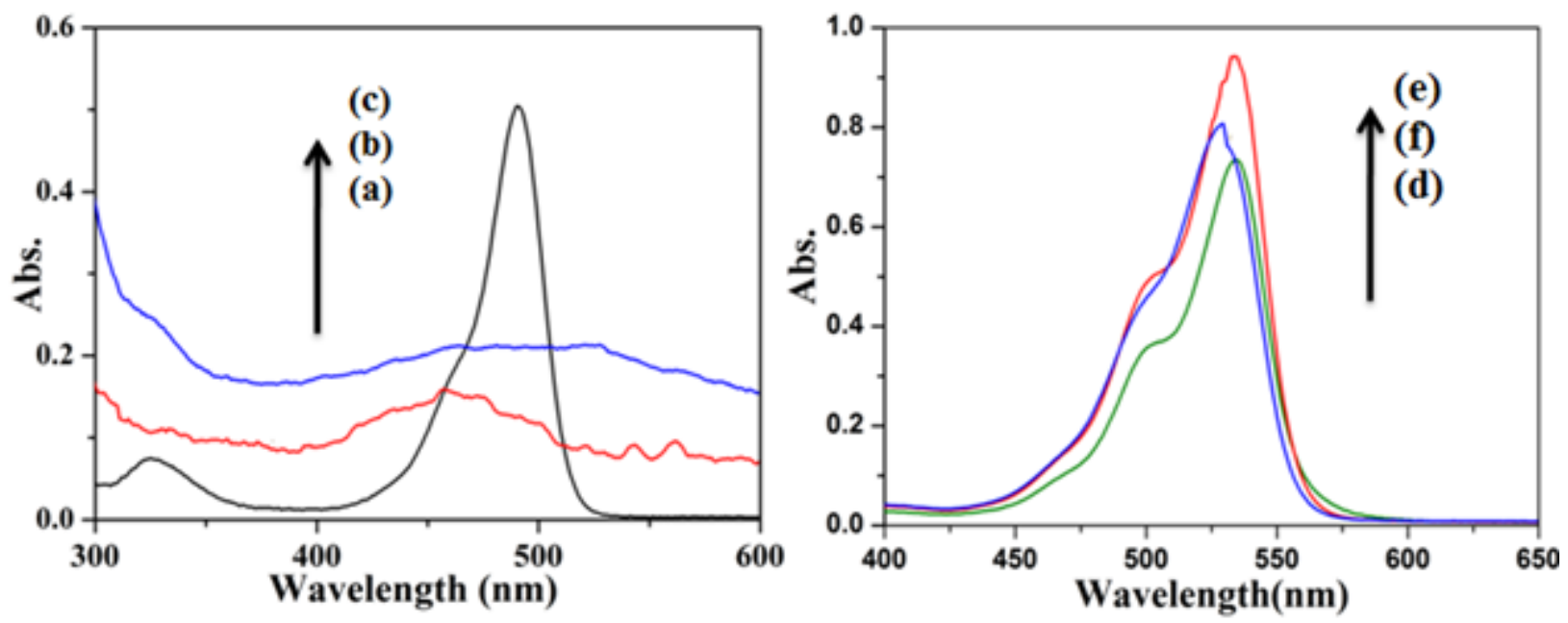

Figure 4

UV-visible spectra of (a) Flur, (b) P1 system, (c) P2 system, (d) R6G, (e) P3 system, (f) P4 system.
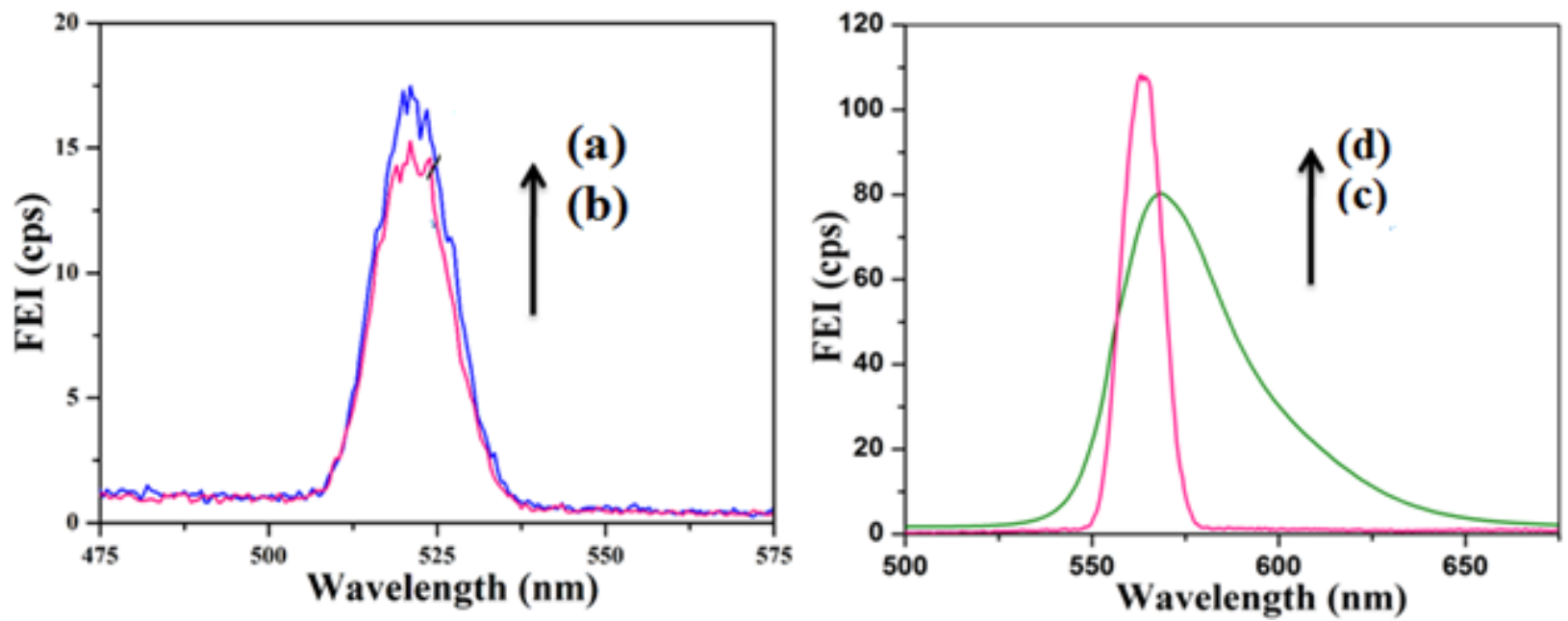

Figure 5

FES of (a) P1 system, (b) P2 system, (c) P3 system, (d) P4 system. 


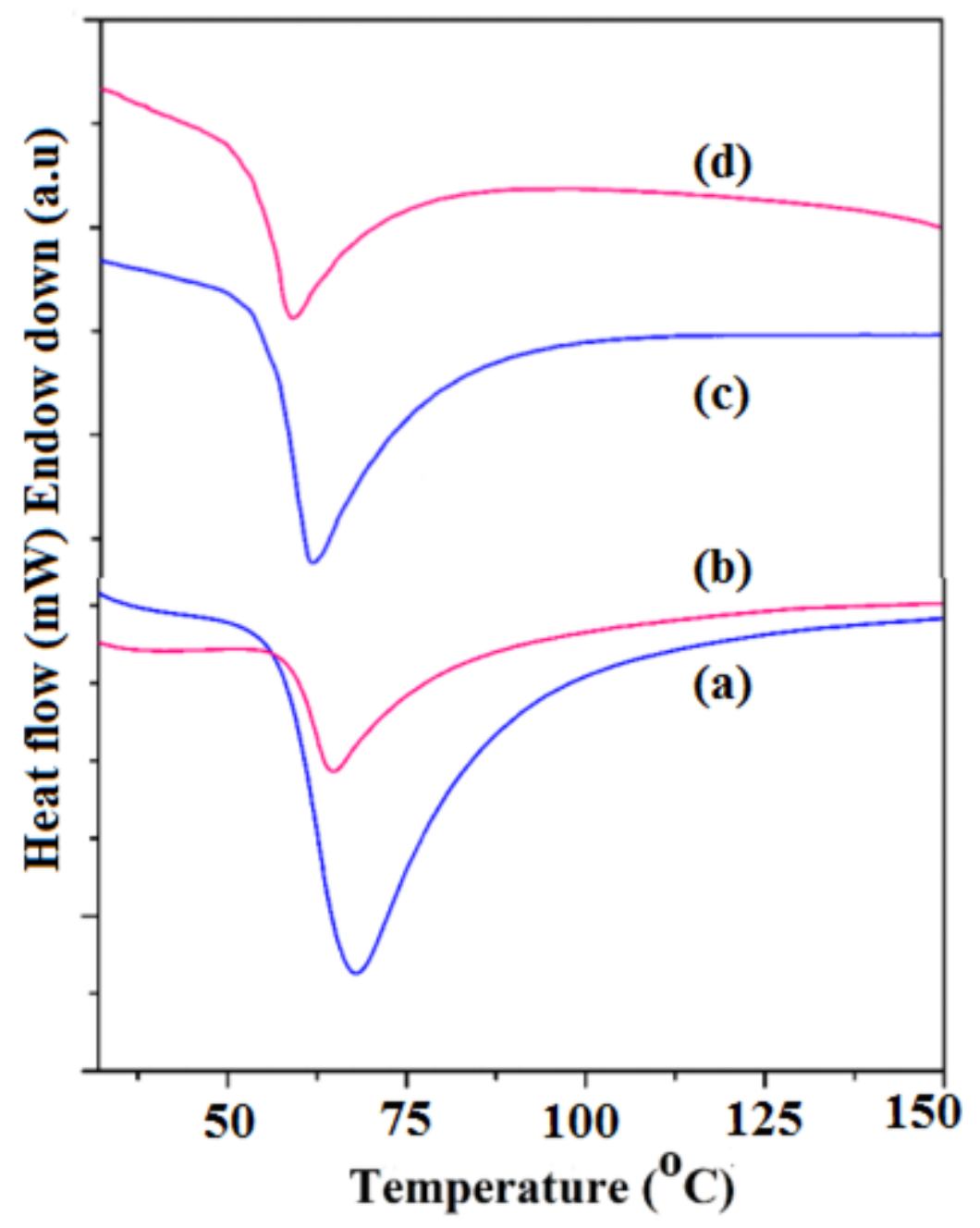

Figure 6

DSC thermogram of (a) P1 system, (b) P2 system, (c) P3 system, (d) P4 system.
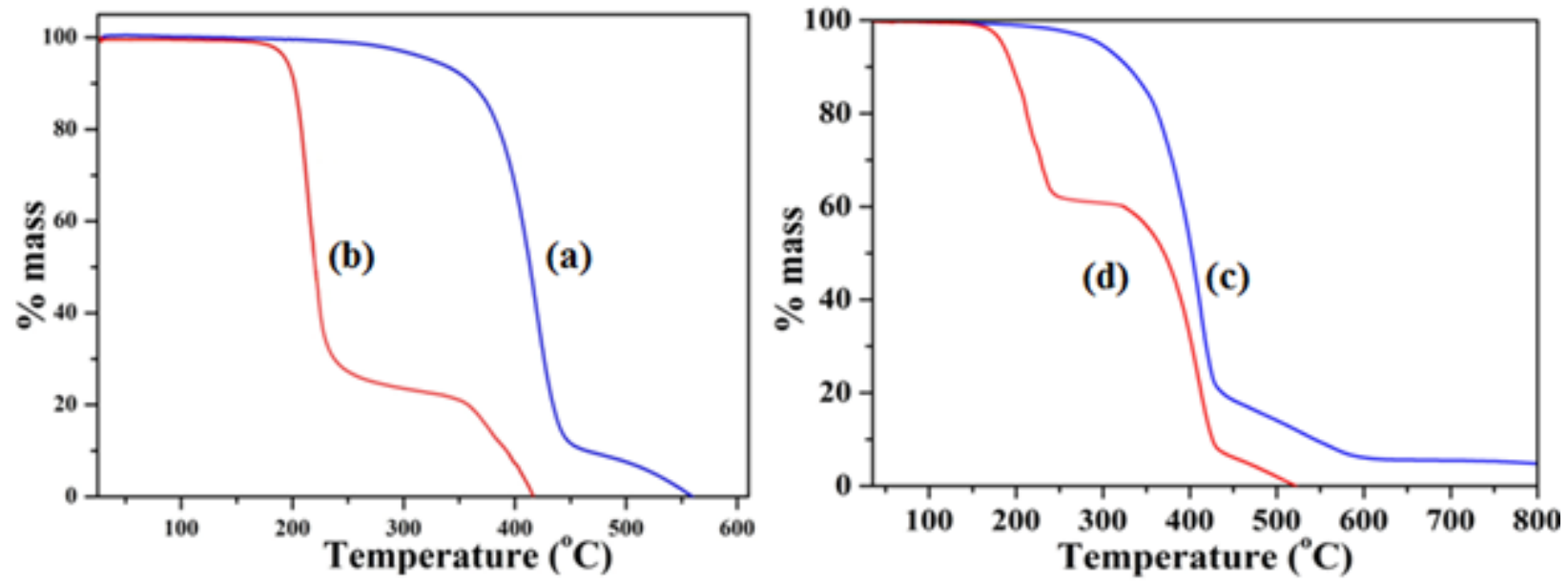

Figure 7

TG thermograms of (a) P1 system, (b) P2 system, (c) P3 system, (d) P4 system. 

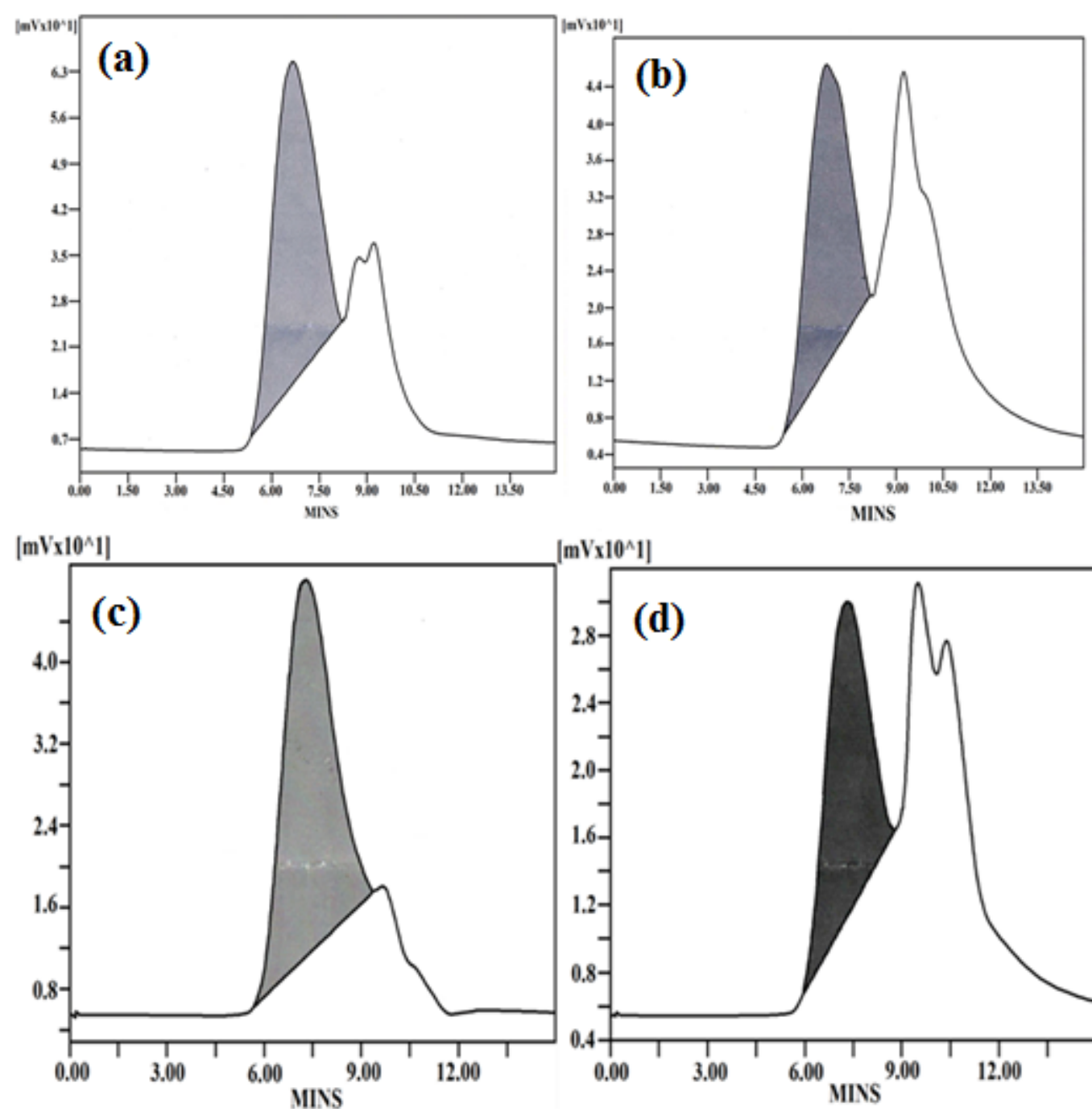

$\left[\mathrm{mVx} 10^{\wedge} 1\right]$

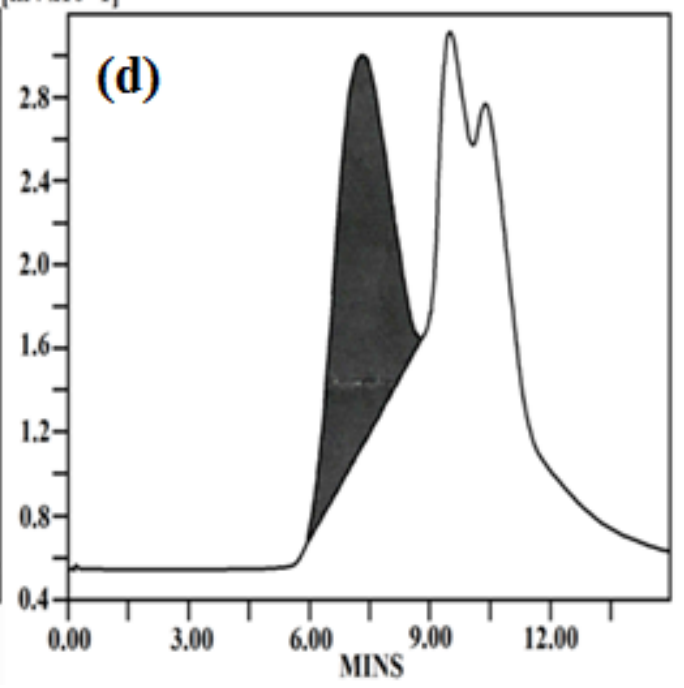

Figure 8

GPC profiles of (a) P1 system, (b) P2 system, (c) P3 system, (d) P4 system. 


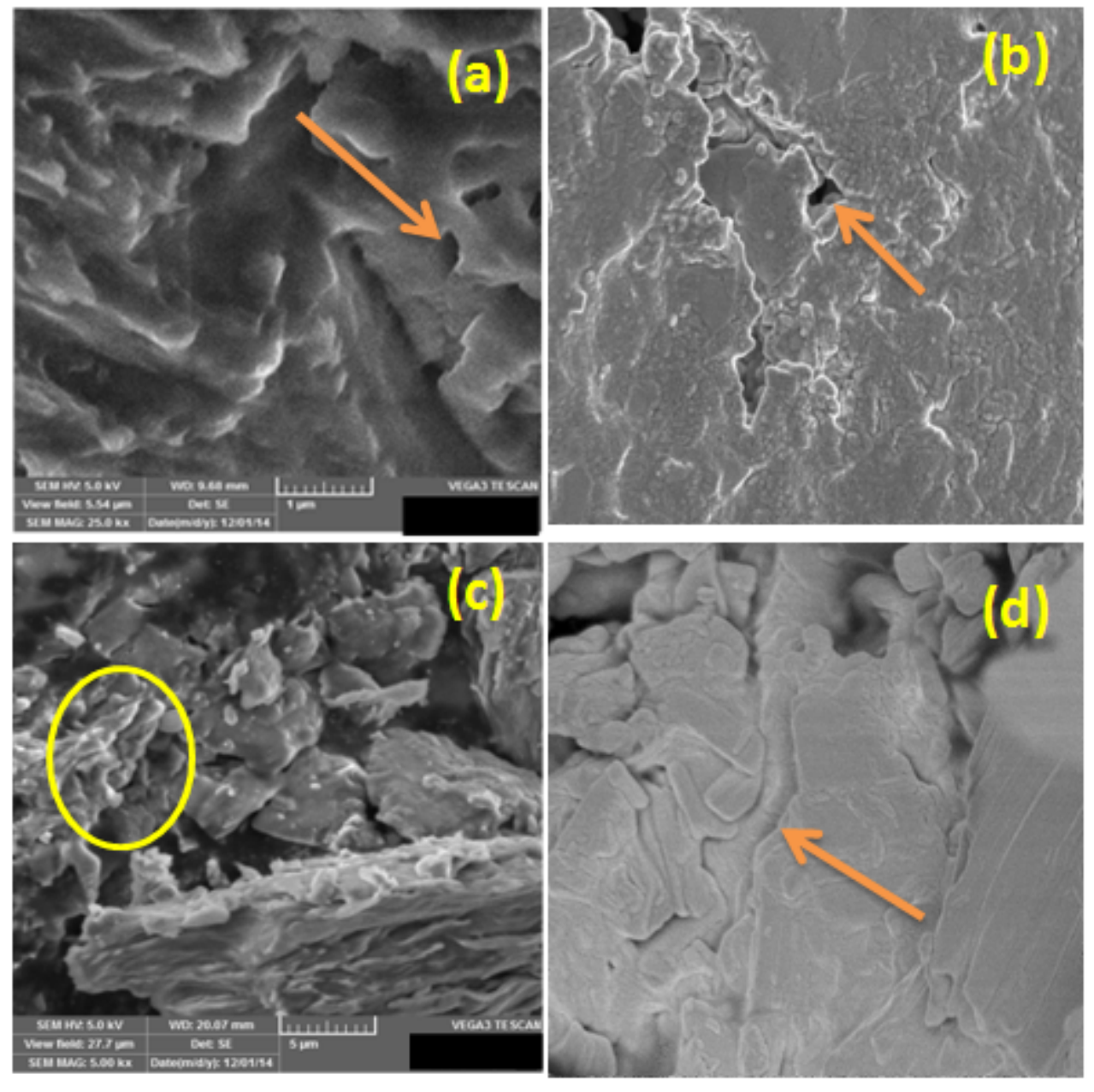

\section{Figure 9}

SEM image of (a) P1, (c) P3 systems and FE-SEM micrographs of (b) P2 system, (d) P4 systems. 

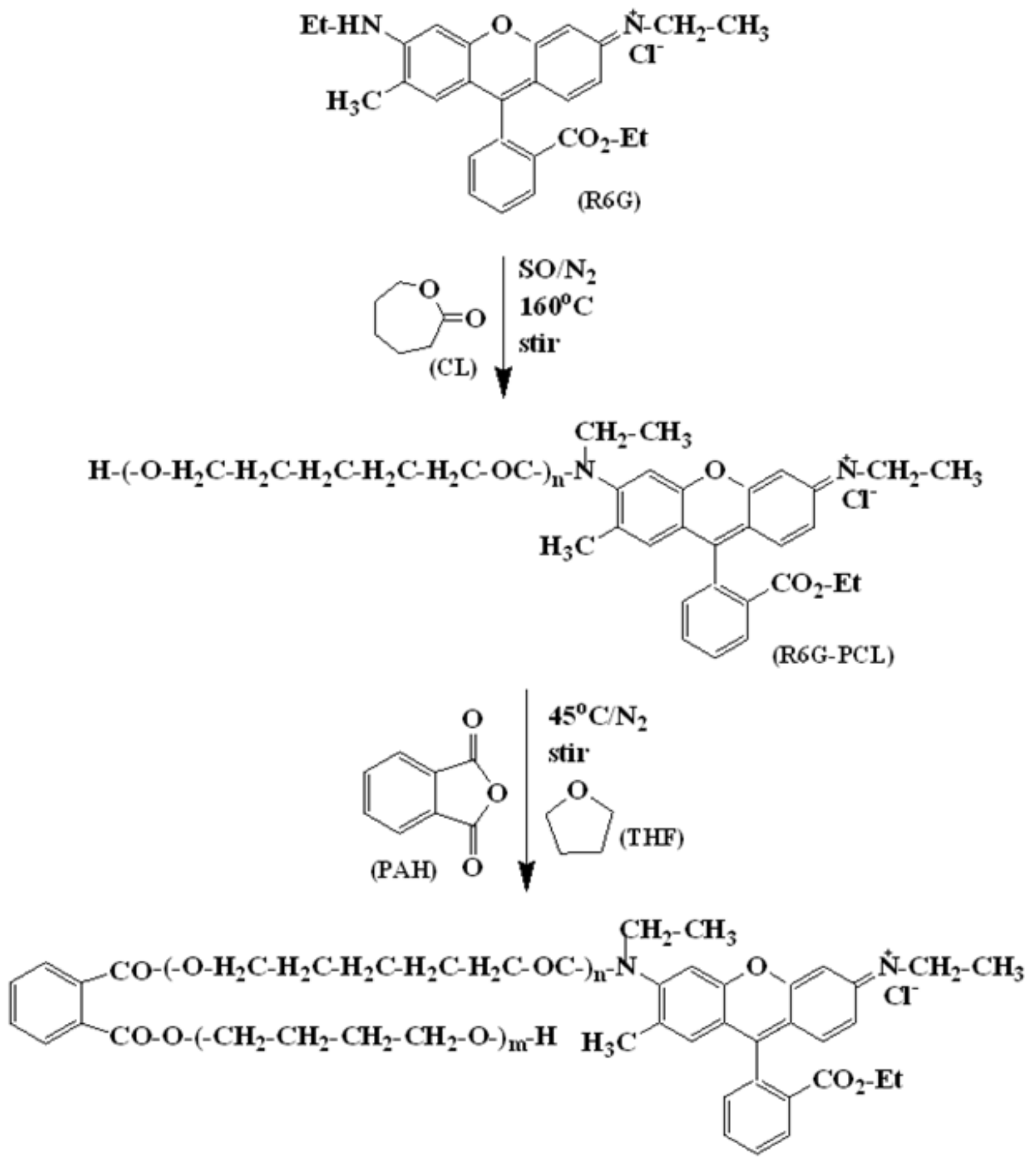

Figure 10

Synthesis of PCL-R6G-PTHF 

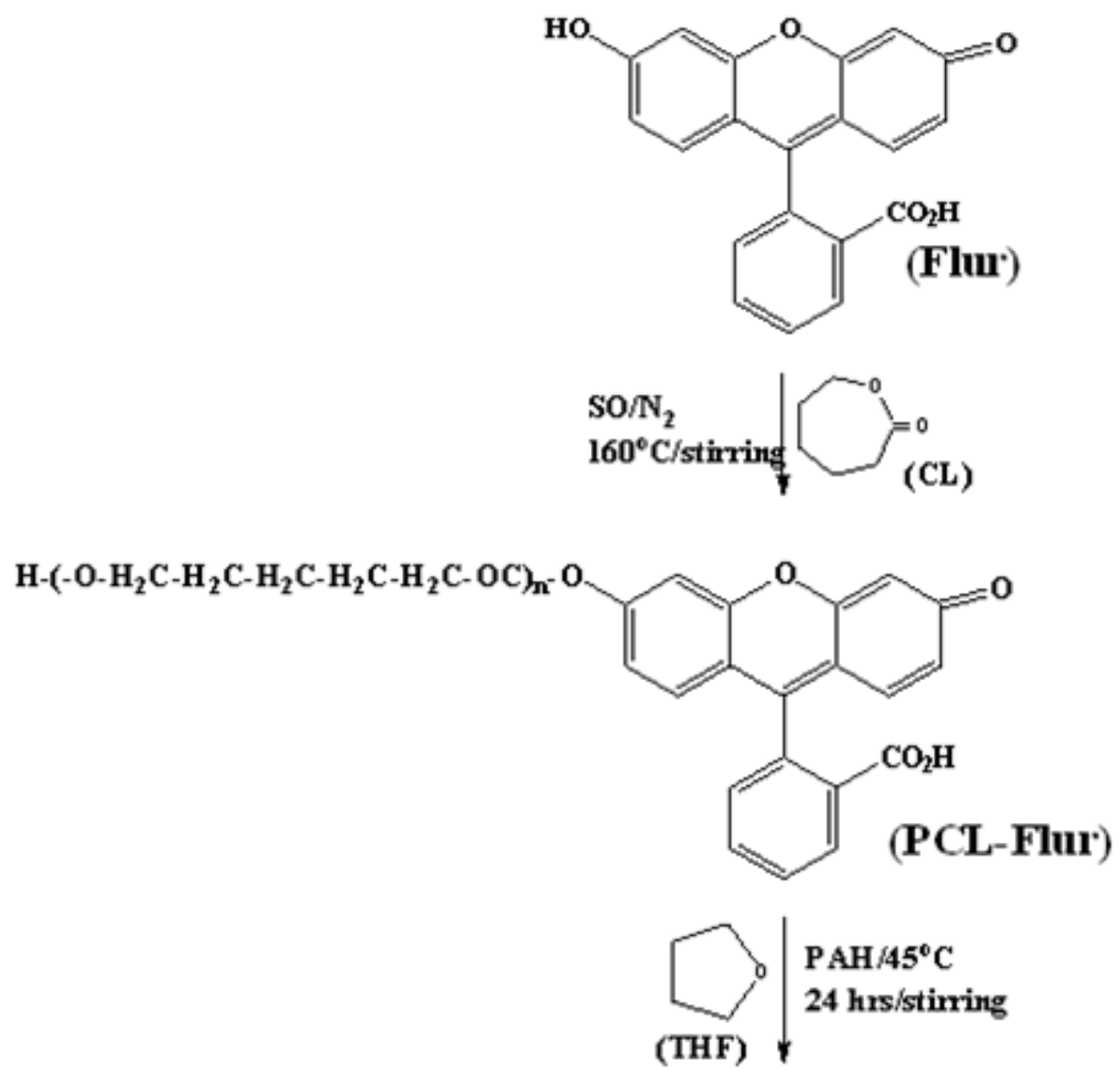

$\mathrm{H}-\left(-\mathrm{O}-\mathrm{H}_{2} \mathrm{C}-\mathrm{H}_{2} \mathrm{C}-\mathrm{H}_{2} \mathrm{C}-\mathrm{H}_{2} \mathrm{C}-\mathrm{H}_{2} \mathrm{C}-\mathrm{OC}\right)_{n}-\mathrm{O}$

Figure 11

Synthesis of PCL-Flur-PTHF 